This item was submitted to Loughborough's Research Repository by the author.

Items in Figshare are protected by copyright, with all rights reserved, unless otherwise indicated.

\title{
New adaptive control strategies for open-end winding permanent magnet synchronous generator(OEW-PMSG) for wind power generation
}

\section{PLEASE CITE THE PUBLISHED VERSION}

https://doi.org/10.1049/icp.2021.1106

\section{PUBLISHER}

Institution of Engineering and Technology

VERSION

AM (Accepted Manuscript)

\section{PUBLISHER STATEMENT}

This paper was accepted for publication in The 10th International Conference on Power Electronics, Machines and Drives (PEMD 2020) and the definitive published version is available at https://doi.org/10.1049/icp.2021.1106.

\section{LICENCE}

CC BY-NC-ND 4.0

\section{REPOSITORY RECORD}

Xing, Ning, Shubo Hu, Zhengyu Lin, Zheng Tan, Wenping Cao, and Shady Gadoue. 2021. "New Adaptive Control Strategies for Open-end Winding Permanent Magnet Synchronous Generator(oew-pmsg) for Wind Power Generation". Loughborough University. https://hdl.handle.net/2134/16438308.v1. 


\title{
NEW ADAPTIVE CONTROL STRATEGIES FOR OPEN-END WINDING PERMANENT MAGNET SYNCHRONOUS GENERATOR(OEW-PMSG) FOR WIND POWER GENERATION \\ Ning Xing', Shubo Hü ${ }^{2}$, Zhengyu Lin ${ }^{3}$, Zheng Tan ${ }^{4}$, Wenping Cao ${ }^{5}$, Shady Gadoue ${ }^{6}$
}

\author{
${ }^{1}$ Aston University, Birmingham, UK \\ ${ }^{2}$ Dalian University of Technology, Dalian, China \\ ${ }^{3}$ Loughborough University, Loughborough, UK \\ ${ }^{4}$ State Grid Corporation of China, Beijing, China \\ ${ }^{5}$ Aston University, Birmingham, UK \\ ${ }^{6}$ Aston University, Birmingham, UK \\ *xingn@aston.ac.uk
}

\begin{abstract}
Keywords: DEADBEAT PREDICTIVE CURRENT CONTROL, MODEL REFERENCE ADAPTIVE CONTROL, MODEL PREDICTIVE CONTROL, OPEN-END WINDING PERMANENT MAGNET SYNCHRONOUS GENERATOR, SLIDING MODE CONTROL
\end{abstract}

\begin{abstract}
A wind turbine system with a new open-end-winding permanent magnet synchronous generator (OEW-PMSG) is studied in this paper, with a focus on torque ripple minimisation of the OEW-PMSG. The problem of torque ripple minimisation of OEWPMSGs is addressed. Generally, the $q$-axis current injection method is employed to suppress the torque ripple. However, the third flux linkage parameters will be affected by high temperature when the machine is operating. In order to solve this problem, two sensorless adaptive control methods are presented in the following paper. The first method is based on adaptive sliding mode control and deadbeat-based predictive current control. The second method is based on model reference adaptive control with deadbeat predictive control. In these two control systems, a zero-sequence back-EMF observer (ZCBO) is used to estimate the zero-sequence back-EMF and zero-sequence current simultaneously and continuously. Meanwhile, the zero-sequence voltage which exists in the zero-sequence path and interferes the ZCBO's performance is considered. The performance of two control strategies is evaluated in MATLAB/SIMULINK environment.
\end{abstract}

\section{Introduction}

Renewable energy is key to establishing future low-carbon economy. Wind energy industry is rapidly growing as wind is only renewable sources of energy which can be utilised in large quantity economically, after hydro energy. In the last three decades, commercial wind turbines have increased in power and size, which have reached $10 \mathrm{MW}$ [1]. The function of wind energy conversion systems (WECS) is to convert the mechanical energy which is captured by the turbine into the electrical energy, and which is fed into the power grid via power electronic converters. Generally, a WECS consists of a wind turbine, an electrical generator, several converters and the grid. Regarding the generators, doubly fed induction generators (DFIGs) are widely used for medium and large wind turbines, as they offer several advantages such as variable speed operation, four-quadrant reactive and active power capabilities [2]. Compared with the synchronous generators with full-rated converters, DFIG-based systems have lower power electronics losses and lower capital costs [3]. However, they need regular maintenance, especially on the slip rings and the gearbox [3]. The use of permanent magnet synchronous generators (PMSGs) in a direct drive topology eliminates the gearbox and slip rings. They have higher efficiency, power density, and high reliability. An open-end- winding PMSG (OEW-PMSG) is chosen in the WECS in this paper. OEW-PMSGs are typically used in traction drives such as electrical vehicles and aerospace applications. However, they haven't been found in use in wind turbine applications.

In the literature [7], to suppress the torque ripple of the OEWPMSM, a $q$-axis current injection method is developed. This method uses zero-sequence back-EMF to counteract the torque ripple. And the zero-sequence back-EMF is obtained by measured zero-sequence current (ZSC) and third zerosequence back-EMF. The third zero-sequence back-EMF is computed by the third flux linkage parameter, measured electrical angular, and measured electrical rotor angle. But, the third flux linkage parameter is estimated by off-line measurement, which is not accurate enough due to the offline error. Additionally, during the machine's operation, high temperature in magnet affects the third flux linkage variation. Theoretically, these disturbances can lead to inaccuracy in the injected q-axis current [6]. To solve this problem and improve the reliability of OEW-PMSM, two sensorless adaptive control methods are presented in this paper. These two methodologies are based on adaptive Sliding Mode Control (SMC) using Deadbeat-based Predictive Current Control (DPCC) and Model Reference Adaptive Control (MRAC) with deadbeat (DB) predictive control. In the meantime, a zero-sequence 
back-EMF observer (ZCBO) is proposed, which can simultaneously and continuously estimate the zero-sequence back-EMF and ZSC in different conditions [6]. Then the estimated current and back-EMF can decrease the disturbances as mentioned above and compensate for one-step control delay. Besides, zero-sequence voltage (ZSV) is also considered in this study. Because of the dead time of the inverter, ZSV still exits in the zero-sequence path although the central hexagon modulation is applied in the PCC. The existence of ZSV affects the accurate performance of ZCBO. Therefore, the consideration of ZSV is innovative for this research.

\section{Structure of open-end-winding PMSG (OEW- PMSG)}

PMSGs have their pros and cons. Their excitation is free, but magnets are expensive. In order to minimise torque ripple and obtain a sinusoidal back-EMF, a Multiphysics approach is necessary when designing machines. Torque ripple is generally produced by the interaction of rotor electromagnetic properties and the stator current magnetomotive forces (MMF) [4]. Depending on different structures of PMSGs, three forms of torque ripple are needed to study. The first one is a result of interaction between stator MMF (mutual torque) and the rotor flux, the second one is based on the interaction between the rotor reluctance (reluctance torque) and the stator MMF, and the third one is commutation torque [4]. For OEW-PMSGs, an adaptive control method to suppress their torque ripple has been attempted previously by some researchers [5], but the performance is varied.

Structurally, an OEW-PMSG has six terminals of the stator windings, and two ends of every stator phase winding which are available to be connected to power converters [6]. Figure 2.1 shows the configuration of the wind energy conversion system structure used in this research. A diode full-bridge rectifier is connected to the terminal of each phase set separately. This topology is a cost-effective and straightforward way to provide unidirectional power flow from the OEW-PMSG to the grid-tied inverter. In the second converter stage, the dc-dc boost converters elevate the voltage of the generator and feed into the DC link. In the last converter stage, a medium-voltage NPC inverter is used to connect to the grid through a three-phase transformer.

Figure 2.2 shows the diagram of the zero-sequence path of OEW-PMSG, and Figure 2.3 shows the diagram of the ZCBO.

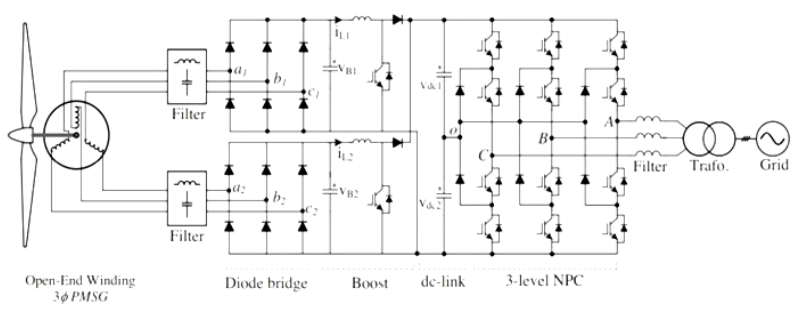

2.1 Wind energy conversion system with open-end winding $P M S G$

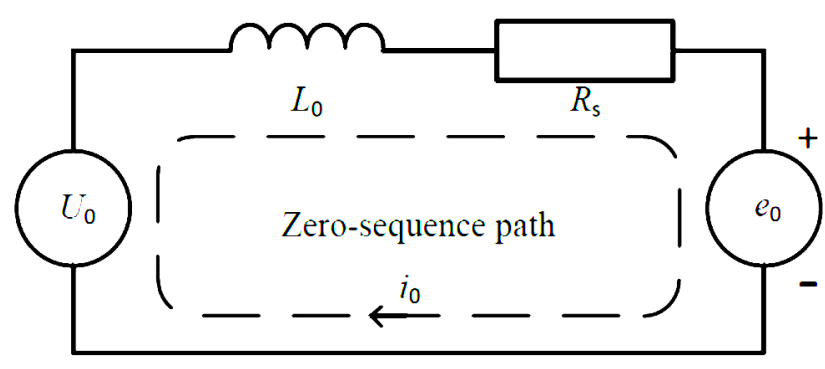

2.2 Zero-sequence path of OEW-PMSG

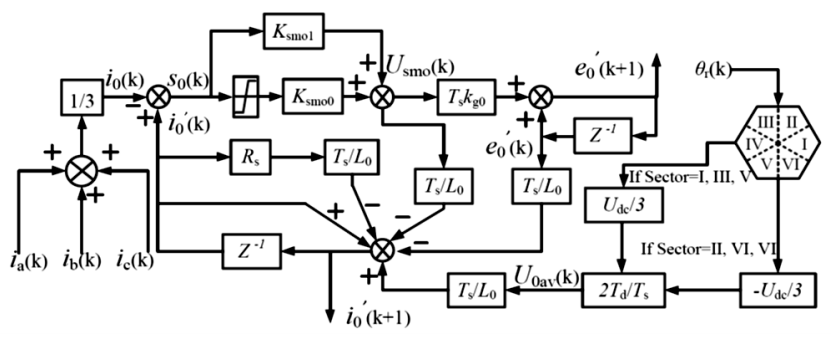

2.3 Diagram of the zero-sequence back-EMF observer

\section{Methodology}

As a control method which is characterized with good static current tracking accuracy, fixed switching frequency, less computation burden, and fast current dynamic response, the deadbeat-based predictive current control (DPCC) is utilized in the first SMC methodology. In the proposed model, a sliding mode speed controller is used in the speed loop, and the discrete deadbeat-based predictive current controller is employed for the current regulation. The proposed scheme is presented in Figure 3.1. Ideally, the proposed control strategy can achieve precise steady-state performance and fast dynamic response. In order to converge the estimated parameters to an adaptive slide mode surface, designing a reliable adaptive sliding mode function is very important for the whole control system [5].

In the proposed methodology, a new adaptive sliding mode function is designed to upgrade the performance of SMC. Meanwhile, the Lyapunov theorem is used in SMC to ensure the convergence of it. The Lyapunov function $\mathrm{V}$ is presented as equation (1), $S_{0}$ is the adaptive sliding mode surface. According to the principle of Lyapunov stability, when the 
Lyapunov function $\mathrm{V}$ satisfies equation (2), the system is stable.

$$
\begin{gathered}
\mathrm{V}=\frac{1}{2} S_{0}^{2} \\
\frac{\mathrm{dV}}{\mathrm{dt}}=S_{0} \frac{d S_{0}}{d t} \leq 0
\end{gathered}
$$

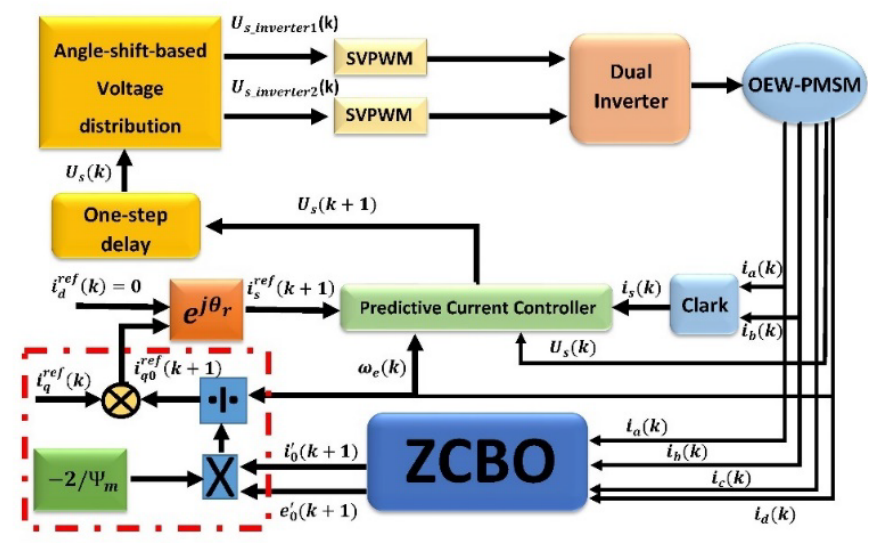

3.1 Sliding mode control with predictive current control with ZCBO for OEW-PMSM

In the literature, the fixed-gain PI controller is generally used to estimate the rotor speed and position of the PMSM. And, the trial-and-error method is mostly adopted to tune the PI controller. Because the machine parameters are continuously changing in operation, fixed-gain PI controller is difficult to tune with accuracy [8]. Therefore, MPC is employed to replace the fixed-gain PI controller in the proposed MRAS observer in this paper. Figure 3.2 shows the structure of this control method.

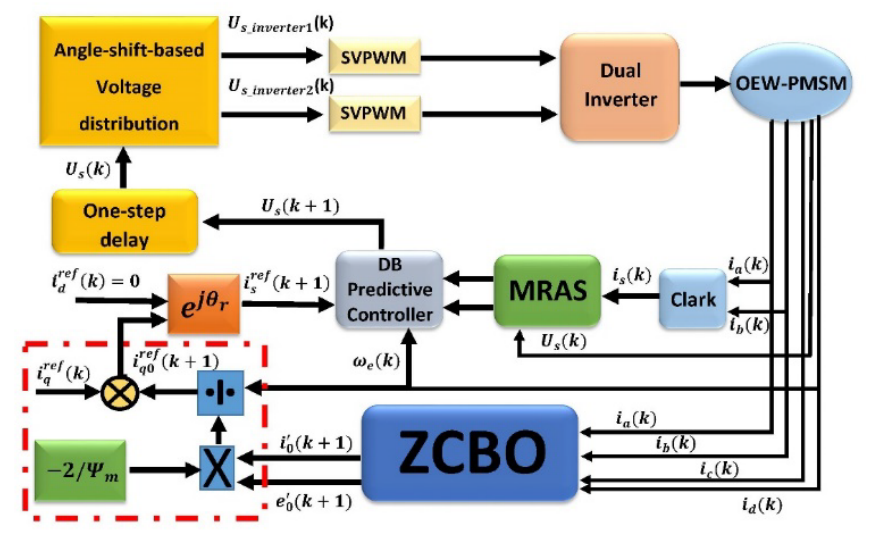

3.2 MRAS with deadbeat predictive controller for OEW$P M S M$

By comparison, the model predictive control (MPC) has an excellent performance on both dynamic and steady-state, so it has been considered as the control method [9]. In different types of MPC approaches, the finite control set-model predictive control (FCS-MPC) is one of the well-known techniques. In order to obtain the predictive system model and applying the optimum switching state, a limited set of switching states is utilized in FCS-MPC [10][11]. The main disadvantage of this proposed FCS-MPC is the existing variable switching frequency which causes a negative impact on the design of the output filter and the converter efficiency [6]. Another popular control scheme is the deadbeat (DB) predictive control, which has constant switching frequency and excellent transient response. In [12], to enhance the robustness of the DB predictive controller, the control approach combines feedforward linearisation with the DB scheme. Because of the outstanding results from previous research, DB predictive controller with feedforward linearisation is chosen in this study. The structural diagram of this controller is shown in Figure 3.3.

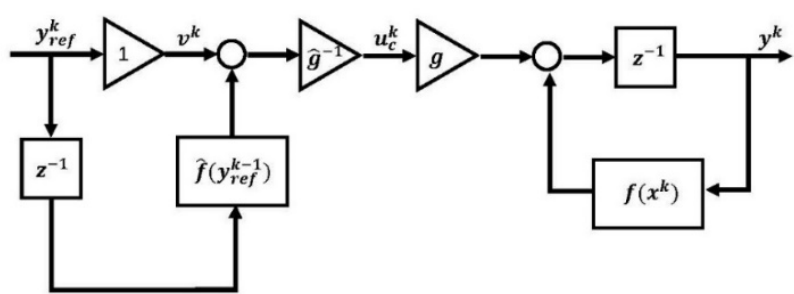

3.3 Structural diagram of the deadbeat controller with
feedforward linearization

\section{Test Results}

For the purpose of testing the performance of the proposed schemes, two models were established in MATLAB/Simulink software. The parameters of OEW-PMSG are shown in Table 1.

Table 1 The parameters of OEW-PMSG

$\begin{array}{cc}\text { Parameter } & \text { Value } \\ \text { Rated power }(\mathrm{W}) & \\ \text { Base power of the electrical generator }(\mathrm{VA}) & 9444.44 \\ \text { Stator resistance } \mathrm{R}(\Omega) & 0.425 \\ \text { Pole pair } & 4 \\ \text { Rotor flux linkage }(\mathrm{Wb}) & 0.433 \\ \text { Inertia J }\left(\mathrm{kg} \cdot \mathrm{m}^{2}\right) & 0.01197 \\ \text { Armature inductance } \mathrm{L}(\mathrm{H}) & 0.000395 \\ \text { Stator inductance } \mathrm{L}(\mathrm{H}) & 0.000835 \\ \text { Viscous damping F }(\mathrm{N} \cdot \mathrm{m} . \mathrm{s}) & 0.001189 \\ \text { The density of air }\left(\mathrm{kg} \cdot \mathrm{m}^{3}\right) & 1.225 \\ \text { Area swept by blades A }\left(\mathrm{m}^{2}\right) & 1.06\end{array}$

The simulation results of Sliding Mode Control (SMC) using Deadbeat-based Predictive Current Control (DPCC) which is based on OEW-PMSG present below. 


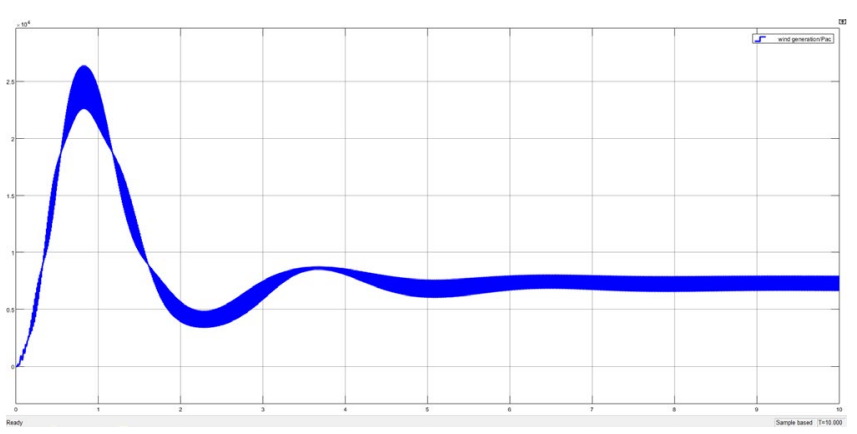

4.1 The waveforms of wind generator active power in SMC$M P C$

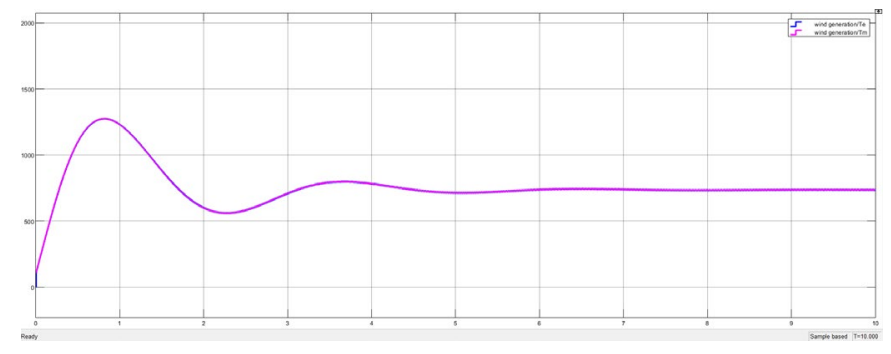

4.2 The waveforms of wind generator Te and Tm in SMC$M P C$

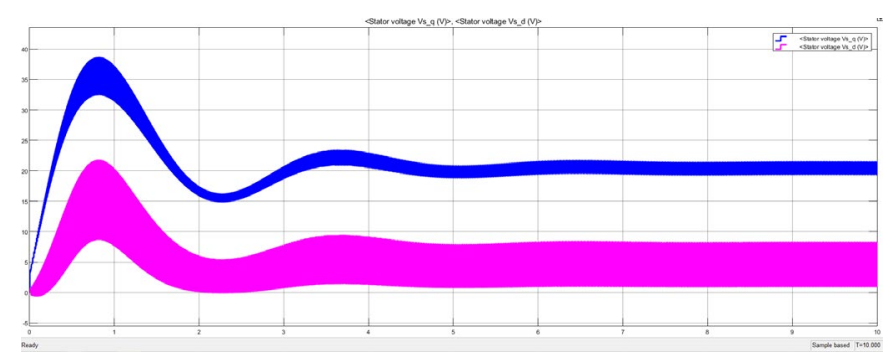

4.3 The waveform of stator $d-q$ voltage in SMC-MPC

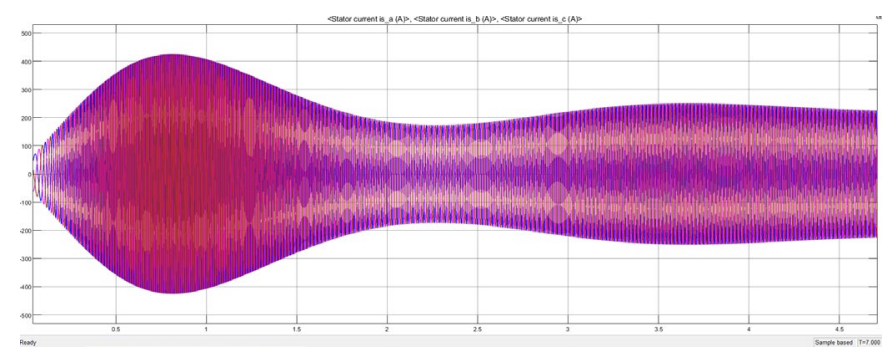

4.4 The waveform of three-phase output current in SMC$M P C$

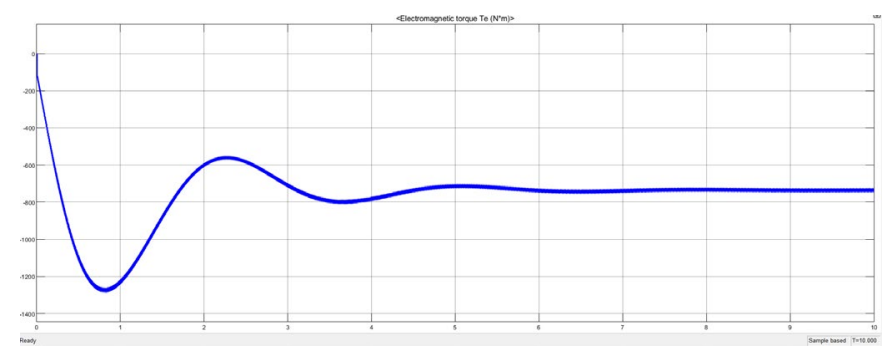

4.5 The waveform of electromagnetic torque Te in SMC$M P C$

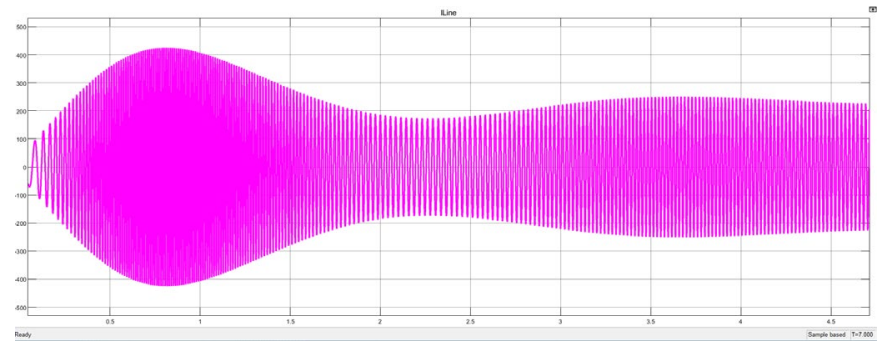

4.6 The waveform of line current in SMC-MPC

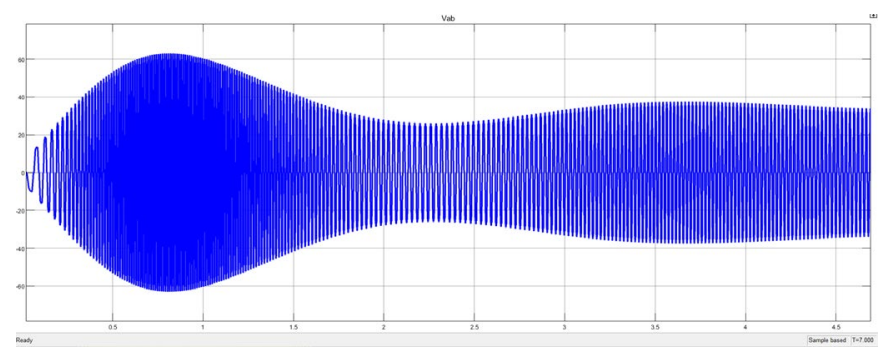

4.7 The waveform of line to line voltage Vab in SMC-MPC

Then, the simulation results of Model Reference Adaptive Control (MRAC) with deadbeat (DB) predictive control which is based on OEW-PMSG show as follows:

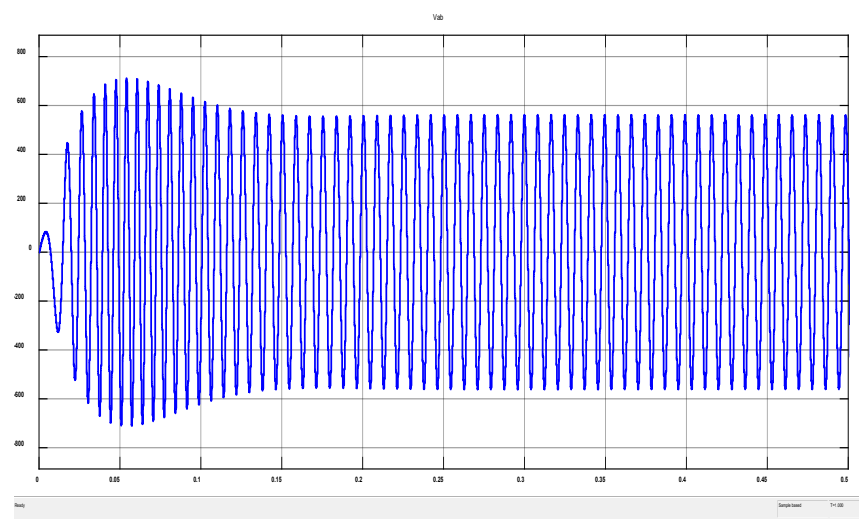

4.8 The waveform of line to line voltage Vab in MRAC-MPC

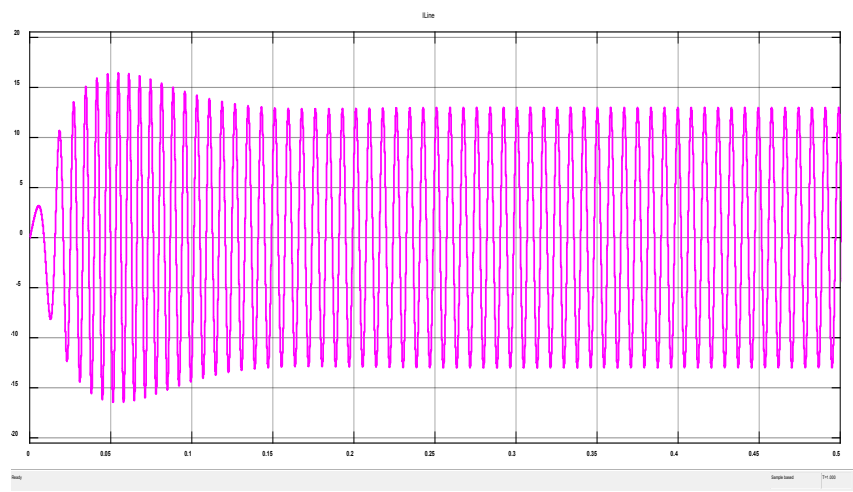

4.9 The waveform of line current in MRAC-MPC 


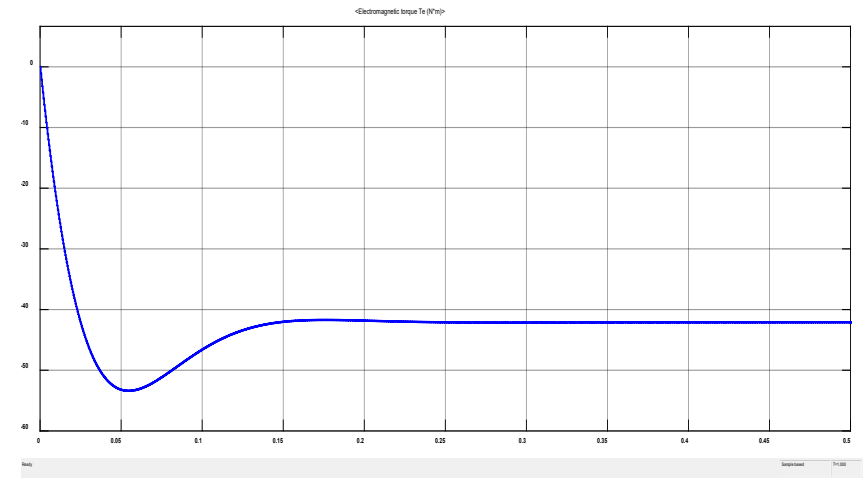

4.10The waveform of electromagnetic torque Te in MRAC$M P C$

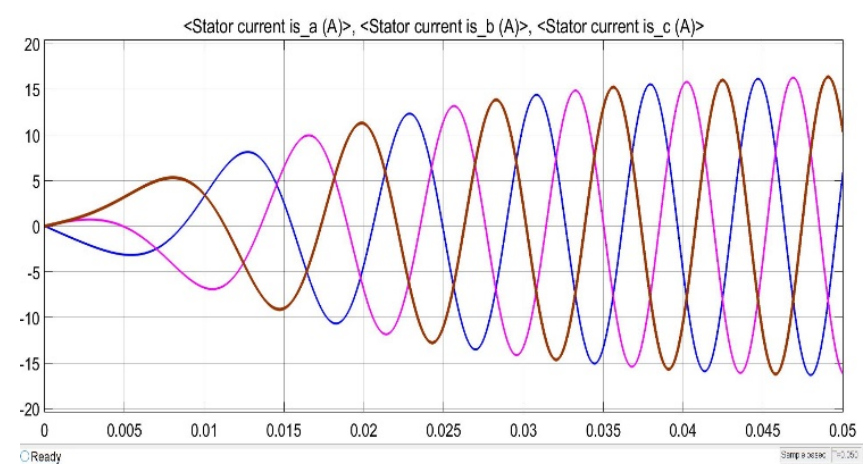

4.11The waveform of three-phase output current in MRAC$M P C$

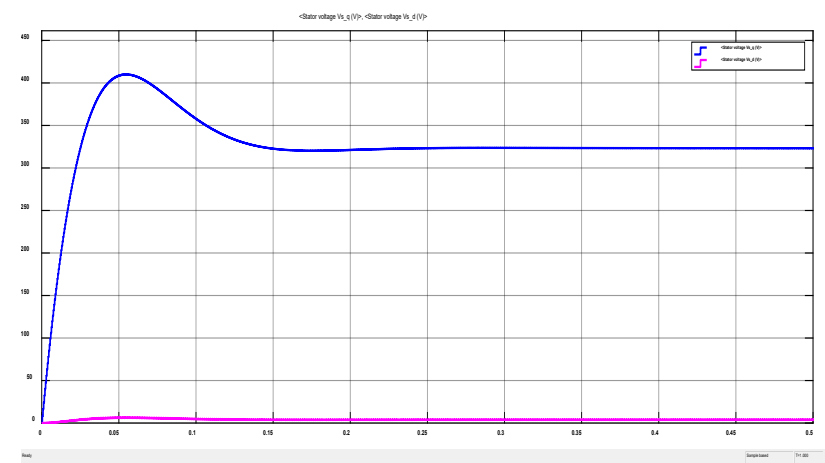

4.12 The waveform of stator $d-q$ voltage in MRAC-MPC

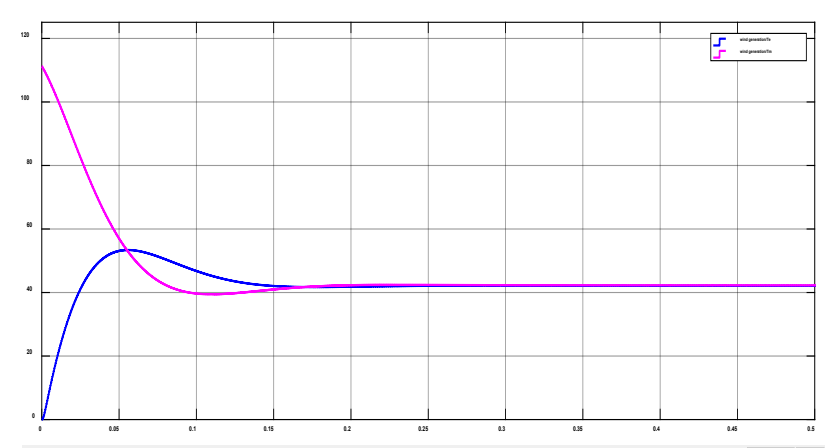

4.13The waveforms of wind generator Te and Tm in MRAC$M P C$

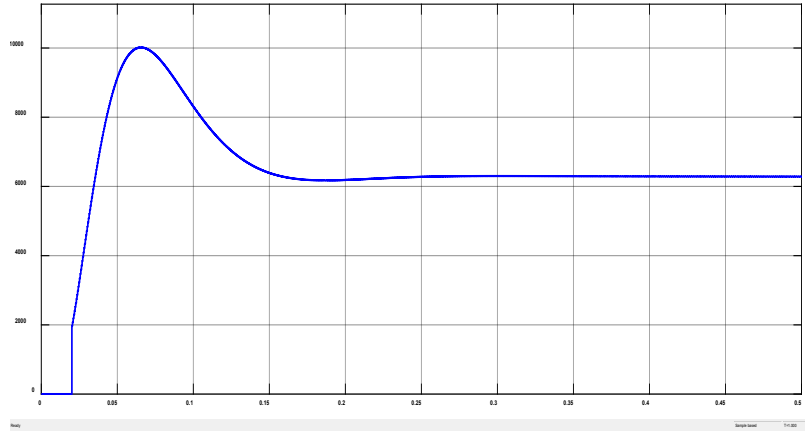

\subsection{The waveforms of wind generator active power in $M R A C-M P C$}

In the second control strategy (MRAS with deadbeat predictive controller for OEW-PMSM), the power reaches at $6123 \mathrm{~W}$ when the wind speed is $12 \mathrm{~m} / \mathrm{s}$. And in first control strategy (Sliding mode control with predictive current control with ZCBO for OEW-PMSM), the power reaches at $6793 \mathrm{~W}$ when the wind speed is $152 \mathrm{~m} / \mathrm{s}$. After a comparison between them, the second method is more stable and more efficient. Therefore, improving the control performance and enhancing the efficiency of the first method could be future work.

\section{Conclusion}

This paper has presented two sensorless adaptive control methods for wind turbine generating system with an open-end winding PMSG. The control and performance of the proposed strategies is evaluated by simulation results. From the results, the second proposed system (Model Reference Adaptive Control with deadbeat predictive control) is proven to be stable and reliable. However, when producing the same active power of the first strategy, the first proposed system (Sliding Mode Control using Deadbeat-based Predictive Current Control) needs a high wind speed. Therefore, continuing to develop the first control method will be the next step of this study.

\section{Acknowledgements}

None

\section{References}

[1]. Prathap. P and Muralidharan. V, "Open-EndWinding PMSG for Wind Energy Conversion System with Dual Boost NPC Converter", International Journal for Research in Applied Science \& Engineering Technology, Volume 2 Issue V, May 2015.

[2]. Müller. S, Deicke. M, and R.W. De Doncker, "Doubly fed induction generator systems," IEEE Industry Applications Magazine, vol. 8, n³, pp. 26-33, May-June 2002.

[3]. Benelghali. S, Benbouzid. M, Charpentier. J, "Comparison of PMSG and DFIG for Marine Current Turbine Applications", https://hal.archives-ouvertes.fr/hal00532656, HAL ID: hal-00532656, 4th Nov 2010.

[4]. Parsa. L, Hao. L, and Toliyat. H. A, "Optimization of Average and Cogging Torque in 3-Phase IPM Motor Drives", 
Proceedings of the IEEE Industry Applications Conference 37th IAS Annual Meeting, Pittsburgh 2002.

[5]. Yuan. X, Zhang. C and Zhang. S, "Torque Ripple Suppression for Open-end Winding Permanent-Magnet Synchronous Machine Drives with Predictive Current Control", IEEE Transactions on Industrial Electronics, DOI 10.1109/TIE.2019.2907506, March 2019.

[6]. Yoo. H. J, Nguyen. T. T and Kim. H. M, "MPC with Constant Switching Frequency for Inverter-Based Distributed Generations in Microgrid Using Gradient Descent", Energies 2019, 12(6), 1156, 25 March 2019.

[7]. Nian. H and Hu. W, "Torque Ripple Suppression Method with Reduced Switching Frequency for OpenWinding PMSM Drives with Common DC BUS," IEEE Transactions on Industrial Electronics, DOI: 10.1109/TIE.2018.2833803, May. 2018.

[8]. Abdelrahem. M, Hackl. C and Kennel. R, "A Robust Encoderless Predictive Current Control Using Novel MRAS Observer for Surface-mounted Permanent Mangent Synchronous Generators", PCIM Europe 2017.

[9]. Matthias. P and Erik. S," Sensorless Model Predictive Direct Current Control Using Novel Second Order PLLObserver for PMSM Drive Systems," IEEE Transactions on Industrial Electronics, Vol..99, pp.1, 2010.

[10]. Islam. K. A, Abdelrahem. M, and Kennel. R, "Efficient Finite Control Set-model Predictive Control for Grid-connected Photovoltaic Inverters", IEEE International Symposium on Industrial Electronics (INDEL), Banja Luka, pp. 1-6, 2016.

[11]. Morel. F, et al., "A Comparative Study of Predictive Current Control Schemes for a Permanent-magnet Sunchronous Machine Drive", IEEE Trans, Ind. Electron., Vol. 56, pp. 2715-2728. 2009.

[12]. Stumper. J. F, Hagenmeyer. V, Kuehl. S, and Kennel. R, "Dead-beat Control for Electrical Drives: A Robust and Performance Design Based on Differential Flatness", IEEE Trans. Power Electron, Vol. 30, No. 8. 4585-4596, 2015. 